\title{
Code STEMI: implementation of a city-wide program for rapid assessment and management of myocardial infarction
}

\author{
Michel Le May MD
}

$\infty \infty$

See related articles by Straus and by Moses

Stephen Moses and Michel Le May are the top-ranked winners of the 2008/09 competition for CIHR/CMAJ Top Canadian Achievements in Health Research. Dr. Le May describes his research project in the following essay. Dr. Moses' essay and synopses of the other 6 winning achievements are available at www.cmaj.ca.

$\mathrm{W}$ e developed a city-wide program to provide primary percutaneous coronary intervention as rapid treatment of acute ST-segment elevation myocardial infarction, a medical emergency where minutes count. ${ }^{1}$ Compared with fibrinolytic therapy, primary percutaneous coronary intervention provides more complete and sustained restoration of blood flow to the affected coronary artery. It also is associated with lower rates of death, reinfarction and stroke. ${ }^{2}$ Our research indicates that primary percutaneous coronary intervention is associated with an in-hospital cost saving of more than $\$ 3000$ per patient compared with fibrinolytic therapy. ${ }^{3}$

Primary percutaneous coronary intervention must be performed promptly to be effective. There is a strong correlation between "door-to-balloon" time and survival. Among patients who undergo the procedure, each 30 minutes of delay increases the relative risk of death at 1 year by $7.5 \%{ }^{4} \mathrm{Be}-$ cause of the increased risk with time, guidelines currently recommend a door-to-balloon time of less than 90 minutes. ${ }^{5,6} \mathrm{~A}$ major barrier to achieving this goal is the delay in transferring patients to a facility where primary percutaneous coronary intervention can be quickly performed. For instance, in 2004, the US National Registry of Myocardial Infarction reported door-to-balloon times of more than 180 minutes for patients who were transferred.?

We developed Code STEMI, a city-wide program for Ottawa, Ontario, a city with a population of 800000 residents and a single ground-based emergency transport system. All patients with ST-segment elevation myocardial infarction are now referred to the University of Ottawa Heart Institute for primary percutaneous coronary intervention. We also developed new protocols for transport by emergency medical services and changed management protocols in emergency departments.

Key elements of the new program include the use of electrocardiography by paramedics before arrival at hospital; permission for ambulance crews to bypass emergency depart-

\section{Key points}

- Implementation of standardized protocols is essential to the success of a city-wide program for rapid treatment of acute ST-segment elevation myocardial infarction.

- The development of such a program requires engagement of all relevant stakeholders, including community and university-affiliated cardiologists, emergency physicians, paramedics and hospital administrators.

- Collaboration with the emergency medical system plays a central role in ensuring the program's success.

ments; permission for emergency physicians to mobilize the catheterization laboratory without consulting a cardiologist or general internist; use of a single-call activation scheme; creation of a dedicated room for patients with ST-segment elevation myocardial infarction at the treatment hospital; implementation of standardized protocols for adjunct medical therapy such as acetylsalicylic acid, clopidogrel and heparin; deliverance of prompt feedback to referring physicians and paramedics; and agreements between hospitals to transfer patients back after the procedure to ensure efficient use of beds. Patients are referred through one of two pathways. The first enables paramedics to interpret the electrocardiogram in the pre-hospital setting and independently refer patients who have ST-segment elevation myocardial infarction to the Ottawa Heart Institute. The second enables emergency physicians at all Ottawa hospitals to refer patients directly to the Ottawa Heart Institute. The development of this new city-wide program required engagement of all relevant stakeholders, including community and university-affiliated cardiologists, emergency physicians, paramedics and hospital administrators.

The Code STEMI program went into full operation on May 1, 2005. During the first year, 344 consecutive patients with ST-segment elevation myocardial infarction were referred to the Ottawa Heart Institute for primary percutaneous coronary

Michel Le May is Director of the Coronary Care Unit Research Group, University of Ottawa Heart Institute, and Professor of Medicine, University of Ottawa, Ottawa, Ont.

Cite as CMAJ 2009. DOI:10.1503/cmaj.091087 
intervention. ${ }^{8}$ About $40 \%$ were referred directly by paramedics. This meant that busy emergency departments across the city were relieved of additional patient loads. The median door-toballoon time was significantly shorter for patients referred directly by paramedics (69 minutes) than for those transferred from other hospitals (123 minutes). A door-to-balloon time of less than 90 minutes was achieved for $80 \%$ of patients transferred from the field, as compared with $12 \%$ of those transferred from other hospitals. The median door-to-balloon time for patients transferred from other hospitals was nearly $60 \mathrm{~min}$ utes faster than the reported time for interhospital transfer in the US National Registry of Myocardial Infarction and approached the results reported in randomized trials. The median door-toballoon time for the entire group was 101 minutes.

The most critical achievement of the Code STEMI program has been improved survival among patients with STsegment elevation myocardial infarction. The in-hospital mortality rate was $10 \%$ among such patients who presented to Ottawa emergency departments between 2002 and 2004. ${ }^{9}$ Once the city-wide program was operational, the rate fell to $4.7 \%$ during the first year. Since then, the rate has remained at less than $5 \%$, a $50 \%$ reduction. The use of primary percutaneous coronary intervention also results in a shorter hospital stay for recovering patients. During the first year of operation, the median length of stay in hospital was only 4 days.

Research associated with the development and implementation of the program has led to pioneering approaches in the evaluation, treatment and timing of intervention for acute STsegment elevation myocardial infarction. Our research has contributed to the following: documentation of the superiority of primary percutaneous coronary intervention over fibrinolytic therapy; ${ }^{10}$ evaluation of the cost savings to the health care system of primary percutaneous coronary intervention compared with fibrinolysis; ${ }^{3}$ documentation of the superiority of a pharmacoinvasive strategy (facilitation of percutaneous coronary intervention with drugs given before cardiac catheterization) compared with fibrinolytic therapy alone; ${ }^{11}$ development of screening tools to accurately assess the ability of advanced care paramedics to independently identify patients with ST-segment elevation myocardial infarction; ${ }^{12}$ and a pilot study of the safety and feasibility of advanced care paramedics independently triaging patients in the field. ${ }^{13}$

Many centres in Canada are adopting or adapting our Code STEMI program. Internationally, many centres are considering adoption of the program.

There are several gaps in our knowledge that need to be addressed to enhance care. Improvement in outcomes of percutaneous coronary intervention with drugs such as fibrinolytic agents $^{14}$ or platelet glycoprotein IIb/IIIa receptor inhibitors given before cardiac catheterization has been disappointing. ${ }^{15}$ However, a systematic review of trials has shown that clopidogrel given before the procedure improves patency of the affected coronary artery as well as survival. ${ }^{16}$ Novel antiplatelet agents such as prasugrel and ticagrelor may also prove to be valuable adjuncts to primary percutaneous coronary intervention. We need to evaluate the safety, feasibility and effectiveness of these agents given early in the field by paramedics.

Some challenges remain. We need to develop strategies to improve timely delivery of primary percutaneous coronary intervention for all regions in Canada. Plans to develop programs such as ours in other jurisdictions will require restructuring and expansion of the current infrastructure of emergency medical services. All ambulances should have equipment to conduct electrocardiography in the field to assist with early diagnosis and rapid triage. Future research needs to focus on methods to increase public awareness regarding the importance of calling for emergency medical services as soon as symptoms of ischemia occur in order to reduce time to reperfusion. Today, the challenge is not just to open the artery but to open it quickly. As Reignier said in Henry VI, "Defer no time, delays have dangerous ends." 17

Competing interests: None declared.

\section{REFERENCES}

1. McNamara RL, Wang Y, Herrin J, et al. Effect of door-to-balloon time on mortality in patients with ST-segment elevation myocardial infarction. J Am Coll Cardiol 2006;47:2180-6.

2. Keeley EC, Boura JA, Grines CL. Primary angioplasty versus intravenous thrombolytic therapy for acute myocardial infarction: a quantitative review of 23 randomised trials. Lancet 2003;361:13-20.

3. Le May MR, Davies RF, Labinaz M, et al. Hospitalization costs of primary stenting versus thrombolysis in acute myocardial infarction: cost analysis of the Canadian STAT Study. Circulation 2003;108:2624-30.

4. De Luca G, Suryapranata H, Ottervanger JP, et al. Time delay to treatment and mortality in primary angioplasty for acute myocardial infarction: every minute of delay counts. Circulation 2004;109:1223-5.

5. Antman EM, Anbe DT, Armstrong PW, et al. ACC/AHA guidelines for the management of patients with ST-elevation myocardial infarction: a report of the American College of Cardiology/American Heart Association Task Force on Practice Guidelines (Committee to Revise the 1999 Guidelines for the Management of Patients with Acute Myocardial Infarction). Circulation 2004;110:e82-292.

6. Armstrong PW, Bogaty P, Buller CE, et al. The 2004 ACC/AHA guidelines: a perspective and adaptation for Canada by the Canadian Cardiovascular Society Working Group. Can J Cardiol 2004;20:1075-9.

7. Nallamothu BK, Bates ER, Herrin J, et al. Times to treatment in transfer patients undergoing primary percutaneous coronary intervention in the United States: National Registry of Myocardial Infarction (NRMI)-3/4 analysis. Circulation 2005;111:761-7.

8. Le May MR, So DY, Dionne R, et al. A citywide protocol for primary PCI in STsegment elevation myocardial infarction. N Engl J Med 2008;358:231-40.

9. So DY, Ha AC, Turek MA, et al. Comparison of mortality patterns in patients with ST-elevation myocardial infarction arriving by emergency medical services versus self-transport (from the prospective Ottawa Hospital STEMI Registry). Am J Cardiol 2006;97:458-61.

10. Le May MR, Labinaz M, Davies RF, et al. Stenting versus thrombolysis in acute myocardial infarction trial (STAT). J Am Coll Cardiol 2001;37:985-91.

11. Le May MR, Wells GA, Labinaz M, et al. Combined angioplasty and pharmacological intervention versus thrombolysis alone in acute myocardial infarction (CAPITAL AMI study). J Am Coll Cardiol 2005;46:417-24.

12. Le May MR, Dionne R, Maloney J, et al. Diagnostic performance and potential clinical impact of advanced care paramedic interpretation of ST-segment elevation myocardial infarction in the field. CJEM 2006;8:401-7.

13. Le May MR, Davies RF, Dionne R, et al. Comparison of early mortality of paramedic-diagnosed ST-segment elevation myocardial infarction with immediate transport to a designated primary percutaneous coronary intervention center to that of similar patients transported to the nearest hospital. Am J Cardiol 2006;98:1329-33.

14. Assessment of the Safety and Efficacy of a New Treatment Strategy with Percutaneous Coronary Intervention (ASSENT-4 PCI) investigators. Primary versus tenecteplase-facilitated percutaneous coronary intervention in patients with STsegment elevation acute myocardial infarction (ASSENT-4 PCI): randomised trial. Lancet 2006;367:569-78.

15. Ellis SG, Tendera M, de Belder MA, et al. Facilitated PCI in patients with STelevation myocardial infarction. N Engl J Med 2008;358:2205-17.

16. Vlaar PJ, Svilaas T, Damman K, et al. Impact of pretreatment with clopidogrel on initial patency and outcome in patients treated with primary percutaneous coronary intervention for ST-segment elevation myocardial infarction: a systematic review. Circulation 2008;118:1828-36.

17. Shakespeare W. Henry VI. Part 1, act 3, scene 2.

Correspondence to: Dr. Michel Le May, University of Ottawa

Heart Institute, 40 Ruskin St., Ottawa ON K1Y 4W7;

fax613 761-4596; mlemay@ottawaheart.ca 